\title{
An in vitro examination on the effectiveness of commercial toothpastes in the prevention of tooth decay, using eggshell as a substitute for human tooth material.
}

SADJ August 2018, Vol 73 no 7 p446 - p451

SC Onwubu ${ }^{1}$, PS Mduli², S Singh ${ }^{3}$, v Bharuth ${ }^{4}$

\begin{abstract}
Background: Despite improvements in oral health status, dental caries remains a public concern. This study examines the effectiveness of commercial toothpastes in the prevention of tooth decay, using eggshell powder as a substitute for human tooth material.
\end{abstract}

Methods: Colgate, Aquafresh, Colgate Sensitive, Sensodyne, and Oralwise were tested. An enamel model was simulated by adding eggshell powder to beakers containing dissolved toothpastes. The contents were agitated for eight hours at 800rpm, filtered and oven dried. Scanning Electron Microscope (SEM) and Energy Dispersive Spectroscopy (EDX) were used to characterise the surface morphology and the calcium and phosphate composition of the toothpastes pre- and post- agitation with eggshell powder. Gas-displacement and pressure sensor tests evaluated the rate of reaction between the substitute "tooth enamel" and acids.

Results: EDX analysis confirmed the presence of calcium phosphate ions, while SEM revealed the formation of an enamel-like layer after agitation. Pressure sensor tests confirmed Colgate Sensitive as most effective in protection against acid attacks, with Oralwise least effective.

Conclusions: Eggshell can be used as a substitute for the human tooth in an in vitro experiment. All the tested brands of toothpaste effectively reduced the acid reaction, which would contribute to the prevention of tooth decay.

1. Stanley Chibuzor Onwubu: MHSc. Dental Sciences, Durban University of Technology (DUT), Durban, South Africa.

2. Phumlane Selby Mdluli: PhD. Chemistry, Durban University of Technology (DUT), Durban, South Africa.

3. Shenuka Singh: PhD. Discipline of Dentistry, University of KwaZulu-Natal (UKZN), Durban, South Africa.

4. Vishal Bharuth: MSc. Microscopy and Microanalysis Unit, University of KwaZulu-Natal (UKZN), Durban, South Africa.

Corresponding author

Stanley Chibuzor Onwubu:

Dental Sciences, Durban University of Technology (DUT), Durban, South

Africa. Cell: +27 71793 0852. E-mail: 21445599@dut4life.ac.za.

\section{ACRONYMS}

SEM: Scanning Electron Microscope

EDX: Energy Dispersive Spectroscopy

Keywords: eggshell powder, toothpaste, dental caries, tooth enamel

\section{INTRODUCTION}

Dental caries, also known as tooth decay, is a common bacterial disease characterised by demineralisation and destruction of hard tissues, usually by the production of acid by bacterial fermentation of undisturbed food debris which has accumulated on the tooth surface..$^{1-3}$ Despite the global improvement in oral health status, Inetianbor et al. ${ }^{4}$ point out that dental caries remains one of the most chronic and prevalent infectious diseases in the world., ${ }^{1,5,6}$ Although dental caries has multifactorial causes, ${ }^{1}$ the dietary lifestyles of the individual ${ }^{2}$ as well as sub-optimal oral hygiene habits ${ }^{7}$ help facilitate the onset of this disease. For instance, it has been reported that the consumption of sweets with high concentrations of glucose, saccharine, or fructose, especially if taken in processed juices, and over a prolonged period play an important role in caries development in children. ${ }^{8}$

Dental caries occurs as a result of the metabolism of bacteria lodging in plaque attached to the tooth, and hence toothpaste and tooth brushing should help reduce the adherence of these microorganisms within the plaque biofilm in the mouth. This is supported by some clinical studies ${ }^{9,10}$ which have shown that regular tooth brushing with well-formulated fluoride toothpaste can reduce the incidence of dental caries. Significantly, the dental health organisation in Nigeria has advocated preventive and prophylactic measures in the management of dental caries through regular hygiene and dietary modifications. ${ }^{4}$ The increased availability and consumption of soft drinks, fruit juices, and sports drinks, ${ }^{11}$ however, make it difficult for individuals to alter their dietary habits. As such, promoting good oral habits through regular brushing with the use of toothpaste may become the most viable option for the oral 
health care provider in the management of dental caries. Brushing of teeth using toothpaste is recognised as the most commonly practiced form of oral hygiene in most countries. ${ }^{12}$ Toothpaste serves as an abrasive which helps in removing dental plaque and food particles from the teeth, ${ }^{13}$ as well as assisting in suppressing halitosis and releasing active ingredients, mainly fluoride. ${ }^{14}$ Goldman, Yee (15) Strong arguments have been presented that toothpaste is the only realistic fluoride strategy in many low-income countries where lack of infrastructure renders fluoridation of water or salt not feasible. ${ }^{15}$ In recent years, the oral health care market has witnessed a boom of different brands of toothpaste, with some claiming to be more effective in protection against acid attack and the prevention of dental caries. But just how effective they actually are remains a question since the continued prevalence of dental caries is still a public health concern. ${ }^{3}$ Thus, it is desirable to evaluate the claims that these commercial toothpastes completely prevent the acid attacks that result in caries.

Previous studies suggested that bovine and enamel models be used when examining the effectiveness of commercial toothpaste against acidic attacks. ${ }^{16,17}$ Also considered as the sole test model was the dissolution of hydroxyapatite $(\mathrm{HA})^{18,19}$ It is generally well known that tooth enamel consists mostly of calcium hydroxyapatite with a molecular formula of $\mathrm{Ca}_{10}\left(\mathrm{PO}_{4}\right)_{6}(\mathrm{OH})_{2}{ }^{20}$ Although hydroxyapatite is a hard and resistant compound, acid $(\mathrm{H}+)$ that is produced, especially after a high-sugar meal, attacks the apatite causing the enamel to dissolve. ${ }^{20,21}$ In this in vitro study, eggshells were used as a substitute for human teeth in the examination of factors associated with tooth decay. Eggshells are natural structures composed of both inorganic and organic components such as 97\% of calcium carbonates in the form of calcite; $1 \%$ magnesium carbonate; $1 \%$ apatite $\left(\mathrm{Ca}_{3}\left(\mathrm{PO}_{4}\right)_{2}\right.$; and $5 \%$ of organic matter. ${ }^{22,23}$ Owing to this unique chemical composition, eggshells have been used either directly or indirectly as a bone substitute in maxillo-facial surgery, ${ }^{24}$ and as source of hydroxyapatite in bone regeneration. ${ }^{25}$ To our knowledge, there is limited research on the use of eggshells in examining the effectiveness of commercial toothpaste in the prevention of dental caries. This in vitro study was therefore designed to test that premise. It also aimed to evaluate whether commercial toothpaste can slow down the rate of reaction between dental enamel and acids.

\section{MATERIALS AND METHODS}

Five different brands of toothpaste were bought from a popular shopping mall located in Durban (South Africa). These toothpastes included: Sensodyne, Colgate Sensitive toothpaste, Aquafresh, Oral-wise and Colgate. The composition, active ingredients and manufacturers of the toothpaste are shown in Table 1. The listed brands of toothpaste were selected on the criteria that they: (1) contained no whitening or herbal formulation that may react with acids and: (2) did contain fluoride in their formulations.

\begin{tabular}{|c|c|c|}
\hline Products & Composition as indicated in the labeling & Manufacturer \\
\hline Colgate & $\begin{array}{l}\text { Sodium monofluorophosphates, Calcium carbonates, Aqua, Sorbitol, Sodium } \\
\text { lauryl sulfate, Aroma, Cellulose gum, Sodium bicarbonate, Tetrasodium } \\
\text { pyrophosphate, Benzyl alcohol, Sodium saccharine, Sodium hydroxide, limonene. }\end{array}$ & Colgate-Palmolive Co. \\
\hline Oralwise & $\begin{array}{l}\text { Sorbitol, Hydrated silica, Deionized water, Propylene, Glycol, Sodium lauryl } \\
\text { sulphate, Essence, Cellulose gum, Carrageenan, Sodium saccharin, Sodium } \\
\text { benzoate, Tetrasodium pyrophosphate, Sodium fluoride, Titanium dioxide. }\end{array}$ & Shoprite Checkers (Pty) Ltd. \\
\hline Colgate Sensitive & $\begin{array}{c}\text { Aqua, Gycerin, Hydrated silica, Sorbitol, Potassium nitrate, PEG-12, Tetrapotassium } \\
\text { pyrophosphate, Sodium lauryl sulphate, Zinc citrate, PVM/MA copolymer, Aroma, } \\
\text { Potassium hydroxide, Xanthan gum, Cellulose gum, Cocamidopropyl betaine, } \\
\text { Sodium fluoride, Sodium saccharin, Eugenol, and Limonene }\end{array}$ & Colgate-Palmolive Co. \\
\hline Sensodyne & $\begin{array}{c}\text { Aqua, Sorbitol, Hydrated silica, Glycerin, Potassium Nitrate, Cocamidopropyl } \\
\text { betaine, Aroma, Xanthan gum, Titanium dioxide, Sodium fluoride, Sodium } \\
\text { saccharin, Sodium hydroxide, Sucralose, and Limonene }\end{array}$ & GlaxoSmithKline \\
\hline Aquafresh & $\begin{array}{c}\text { Aqua, Hydrated silica, Sorbitol, Glycerin, Sodium lauryl sulphate, Xanthan } \\
\text { gum, Aroma, Titanium dioxide, PEG-6/PEG-8, Sodium fluoride, Sodium } \\
\text { saccharin, Carrageenan, and Limonene }\end{array}$ & GlaxoSmithKline \\
\hline
\end{tabular}

\section{Preparation of the eggshell powder}

Eggshells collected from food outlets were washed to remove impurities, disinfected by immersion in a diluted solution of household sodium hypochlorite for six hours and then vacuum dried for $\pm 6-9$ minutes at $250^{\circ} \mathrm{C}$. Thereafter, $20 \mathrm{~g}$ of the eggshell was placed in a $250 \mathrm{ml}$ stainless jar (inner diameter of $100 \mathrm{~mm}$ ), together with 10 stainless steel balls of $10 \mathrm{~mm}$ diameter and dry-milled in a planetary ball mill (Retsch ${ }^{\circledR}$ PM 100) at 400 rpm for 20 minutes. The collected powder was then sieved to a particle size of $\leq 25 \mu \mathrm{m}$ using a mechanical sieving machine (Retsch AS 200, Germany).

\section{Simulating tooth using eggshell powder}

Three grams of each brand of the toothpastes listed in Table
1 were dissolved in a beaker containing $100 \mathrm{~cm}^{3}$ deionised water by constant agitation using a magnetic stirrer at 800 rpm for 20 minutes. One gram of the prepared eggshell powder was added to the beaker containing the dissolved toothpaste and the contents agitated for eight hours at a speed of $800 \mathrm{rpm}$. The mixtures were then filtered and subsequently oven dried at 60 degrees for three hours. Six sample groups were used in this experiment, five containing eggshell powder and dissolved toothpaste (test groups), while the sixth, eggshell powder dissolved in $100 \mathrm{~cm}^{3}$ deionised water, was used as the control group. Energy dispersive $\mathrm{x}$-ray spectroscopy in conjunction with a scanning electron microscope (Field Emission-Carl Zeiss), operating at controlled atmospheric conditions at $20 \mathrm{kV}$, were used to determine the elemental composition 
of the samples and to examine the surface morphology. Prior to SEM observation, the surface was coated with a thin, electric conductive gold film to prevent a build-up of electrostatic charge. As a proxy measure, samples of pre and post agitation of eggshell powder with toothpaste were characterised to establish the formation of a calcium hydroxyapatite layer.

Methods of evaluating the effectiveness of the toothpaste in prevention of tooth decay

The effectiveness of the commercial toothpaste against acid attack was evaluated using $2 \mathrm{M}$ hydrochloric acid. This was prepared by diluting $9.6 \mathrm{~mL}$ of acid with deionised water in a $500 \mathrm{~mL}$ volumetric flask.

\section{Gas displacement test}

A gas-displacement test was used to quantify and measure the rate of reaction by observing the displacement of gas formed during the experiment. This entailed using a cylindrical tube of two $\mathrm{cm}$ inner diameter and of $60 \mathrm{~cm}$ in height as the gas displacement test set-up. As illustrated in Figure 1, a $250 \mathrm{~mL}$ Schott bottle, sealed using an airtight stopper, was used for the experiment. A tube was firmly attached through the stopper and connected to a cylindrical tube placed in a reservoir of deionised water. With the aid of a vacuum pump, water from the reservoir was drawn into the cylindrical tube. Prior to the gas displacement test, the initial height of the water in the cylindrical tube was marked using a permanent marker. $0.5 \mathrm{~g}$ from each samples were placed in the Schott bottle, while $50 \mathrm{~mL}$ of the prepared 2 $\mathrm{M} \mathrm{HCl}$ was used as the acid reactant. After 20 minutes, the volume of gas displaced was measured again as the final height of displacement. The amount of gas formed was calculated using equation 1 below.

$V=\pi r^{\wedge} 2 h$. .equation 1

Where " $\vee$ " is the volume of the cylinder, " $\pi$ " is a constant, approximated as 3.142, "r" the radius of the cylinder and "h" is the displaced height of the cylinder.

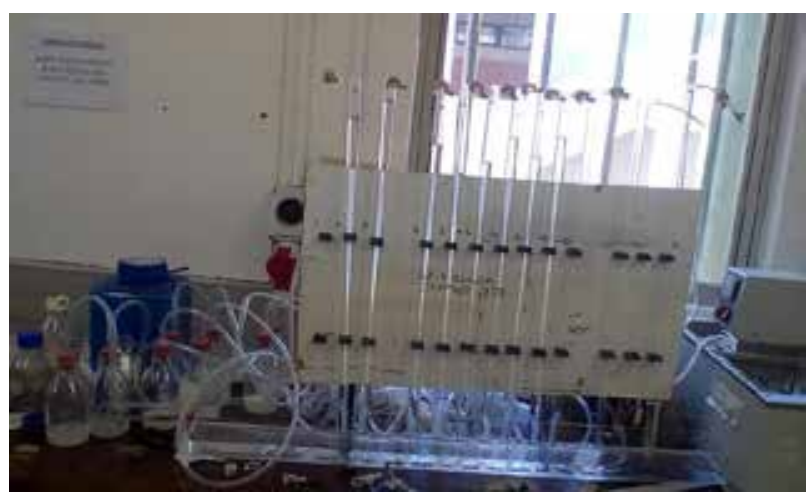

Figure 1: A typical gas-displacement test set-up

\section{Pressure sensor test}

A gas pressure sensor was used to monitor pressure changes $(\mathrm{kPa})$ against time $(\mathrm{s})$ during the reaction of the toothpastes samples with $2 \mathrm{M} \mathrm{HCl}$ acid. As shown in Figure 2, an Erlenmeyer flask $(250 \mathrm{~mL}$ ) served as the reaction container during the pressure test, with $0.5 \mathrm{~g}$ of each sample being placed sequentially in the flask, while $25 \mathrm{~mL}$ of the prepared $2 \mathrm{M} \mathrm{HCl}$ was used as the acid reactant. A stopper fitted with plastic tubing was inserted into the flask to provide an airtight container. The tubing lead to a gas pressure sensor (Order

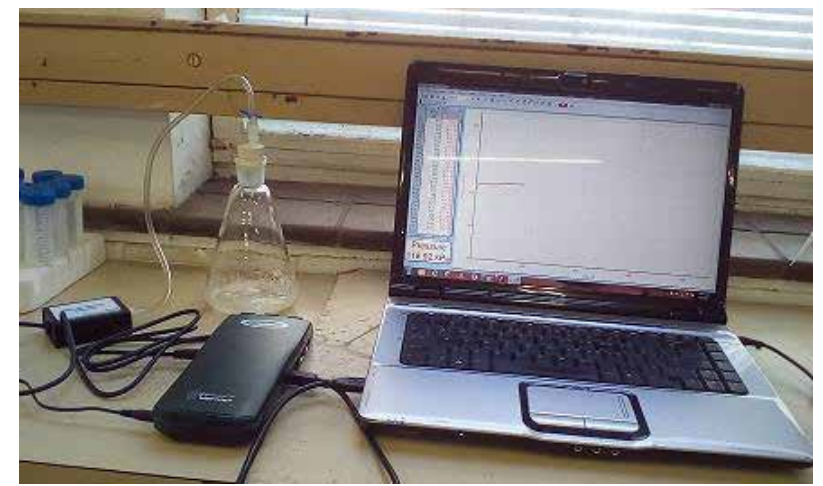

Figure 2: A typical pressure sensor test set-up

Code GPS-BTA). With the aid of an interface system (Vernier LabPro) attached to a computer, the pressure readings were collected and analysed using LoggerPro 3 software.

\section{RESULTS}

\section{Characterisation of eggshell powder tooth} substitute model

Table 2 illustrates the elemental composition of the various toothpastes brands pre and post agitation with eggshell powder. Significant differences in the amounts of calcium and phosphorus content in the brands of toothpaste were observed between pre and post agitation. In particular, excluding Colgate Sensitive brand of toothpastes, there was a noticeable increase in phosphorus content in the toothpaste samples after agitation with eggshell powder. All the brands of toothpaste containing hydrated silica (Table 1) recorded the presence of calcium after agitation.

\begin{tabular}{|c|c|c|c|c|c|c|}
\hline \multirow{2}{*}{$\begin{array}{l}\text { Sample } \\
\text { Group }\end{array}$} & \multicolumn{3}{|c|}{ Pre agitation } & \multicolumn{3}{|c|}{ Post agitation } \\
\hline & $\mathrm{Ca}$ & P & 0 & $\mathrm{Ca}$ & $P$ & 0 \\
\hline Colgate & 34.04 & 0.02 & 50.03 & 25.38 & 0.09 & 52.47 \\
\hline Oralwise & 0 & 0.01 & 45.93 & 31.6 & 0.22 & 41.54 \\
\hline $\begin{array}{l}\text { Colgate } \\
\text { sensitive }\end{array}$ & 0 & 0.53 & 48.94 & 22.12 & 0.37 & 54.05 \\
\hline Sensodyne & 0 & 0.06 & 62.41 & 34.99 & 0.31 & 42.51 \\
\hline Aquafresh & 0 & 0 & 55 & 9.84 & 0.04 & 49.21 \\
\hline
\end{tabular}

The SEM micrograph shown in Figure 4-7 revealed differences in the surface morphology pre and post agitation with eggshell powder. For the Colgate brand of toothpaste shown in Figure 3, for example, it can be observed that the surface morphology of toothpaste
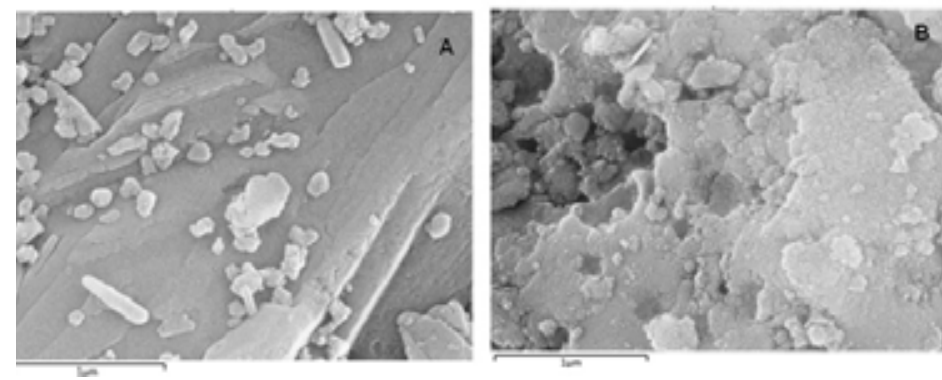

Figure 3: SEM micrographs of Colgate toothpaste samples (A) pre agitation; (B) post agitation with eggshell powder. 
became more compact and dense post agitation with eggshell powder (Figure 3B), compared with the brand pre agitation (Figure $3 \mathrm{~A}$ ). Similar patterns and compactness in the toothpaste after agitation were observed for the other brands of toothpaste (Figures 4 to 7 ).
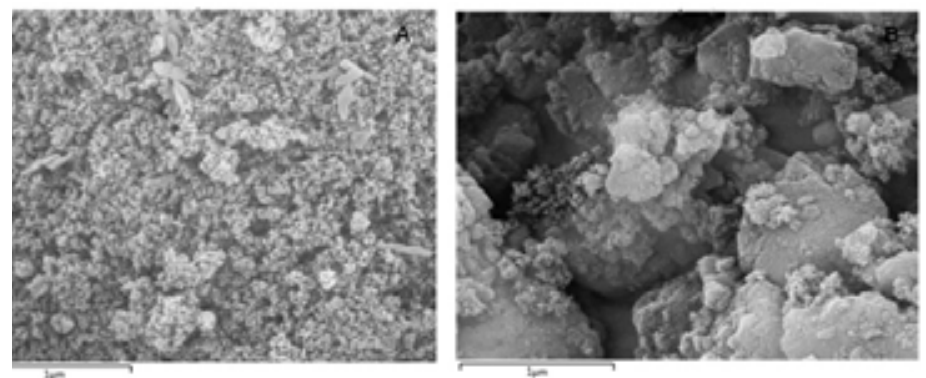

Figure 4: SEM micrographs of Colgate Sensitive toothpaste (A) pre agitation; (B) post agitation with eggshell powder.
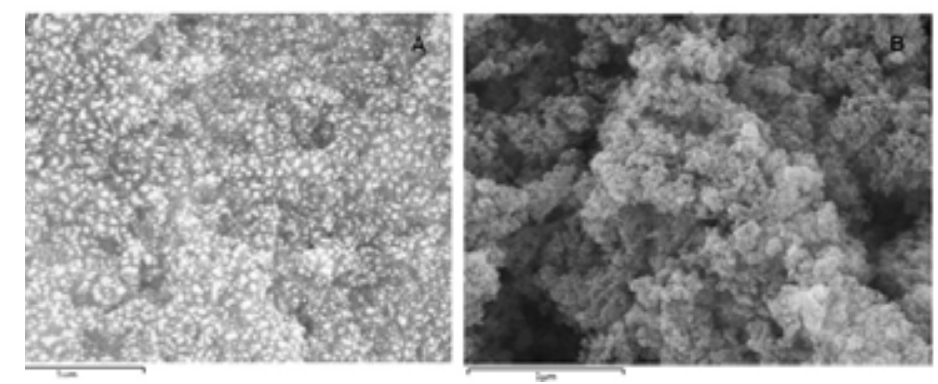

Figure 5: SEM micrographs of Sensodyne toothpaste (A) pre agitation; (B) post agitation with eggshell powder.
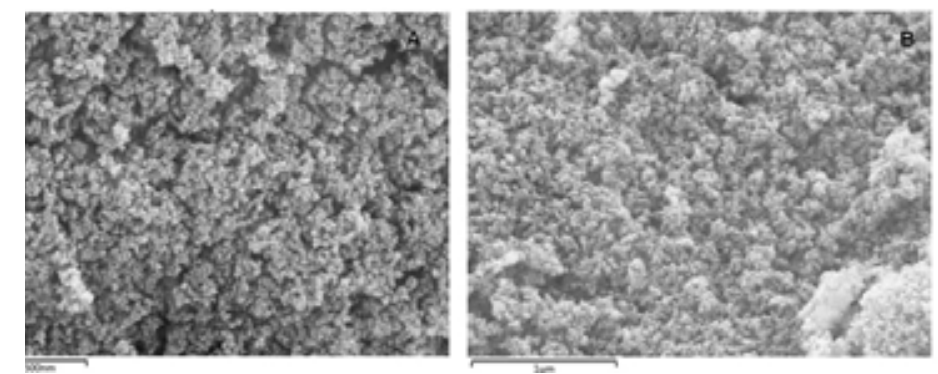

Figure 6: SEM micrographs of Oralwise toothpaste (A) pre agitation; (B) post agitation with eggshell powder.
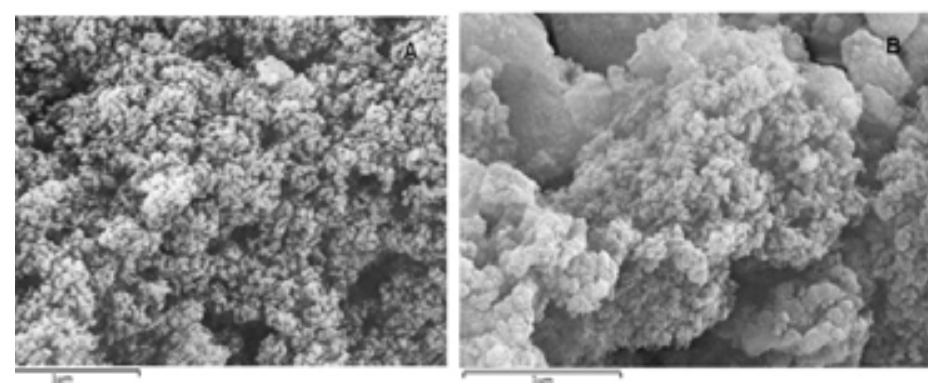

Figure 7: SEM micrographs of Aquafresh toothpaste (A) pre agitation; (B) post agitation with eggshell powder

Acid resistance properties of commercial toothpastes

Figure 8 illustrates the results of the gas-displacement test from the various brands of toothpastes after reaction with $2 \mathrm{M} \mathrm{HCl}$ acids. In contrast to the control sample (eggshell powder dissolved in water), the various brands of toothpastes generated a lesser volume of gas. The amount of gas produced is in accord with the average mean pressure of gas measured in the gas pressure tests (Figure 9). Overall, it can be gathered that the Aquafresh brand of toothpastes generated the least amount of gas in reaction to the acid when compared with the rest of the brands.

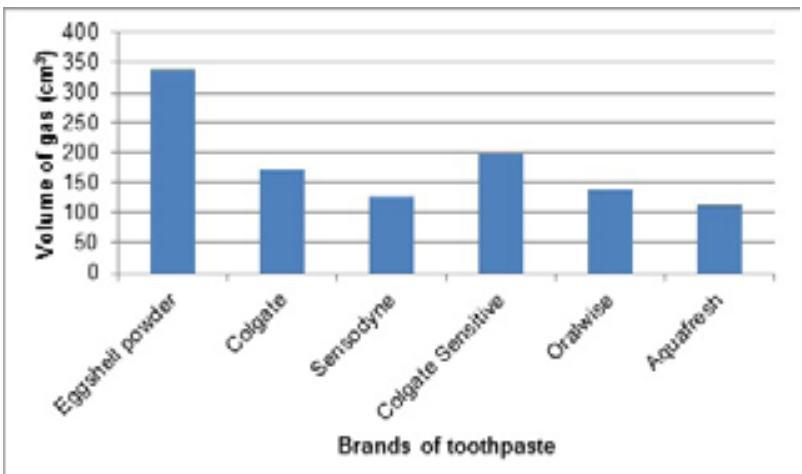

Figure 8: Showing mean gas displacement of the brands of toothpastes reacted with $2 \mathrm{M} \mathrm{HCl}$ acids.

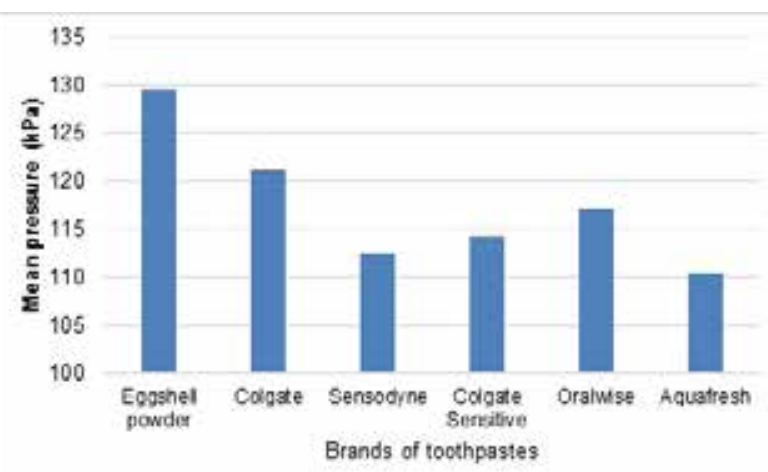

Figure 9: Showing mean gas pressure produced during the reaction of $2 \mathrm{M}$ $\mathrm{HCl}$ acids with the brands of toothpastes.

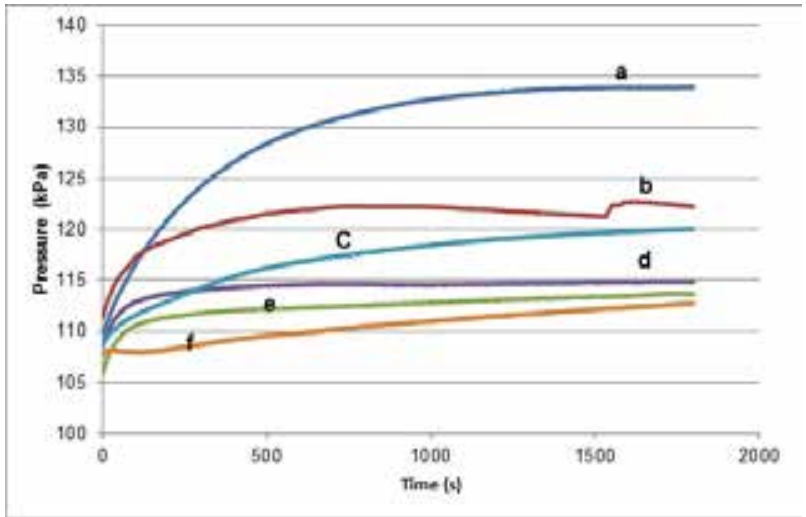

Figure 10: The amount of gas produced during acid reaction with

(a) eggshell powder; (b) Colgate; (c) Aquafresh; (d) Colgate Sensitive; (e) Sensodyne; (f) Oralwise through to 1800 seconds.

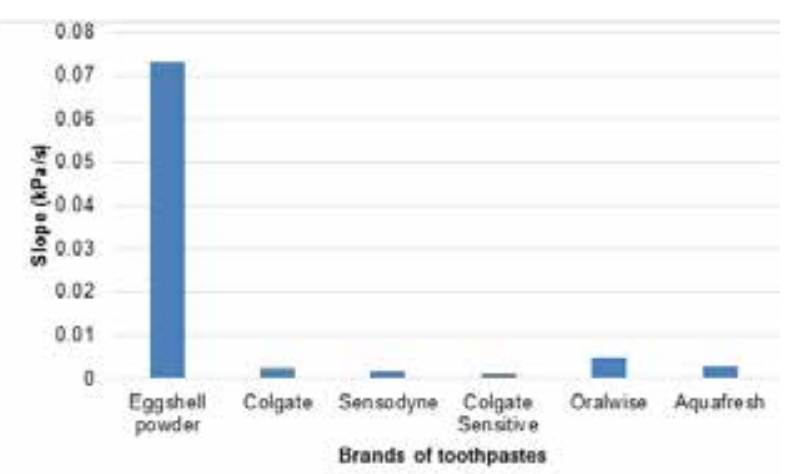

Figure 11: The gas pressure produced during the reaction of $2 \mathrm{M} \mathrm{HCl}$ acids with the brands of toothpastes.

The amount of pressure $(\mathrm{kPa})$ generated during the gas test was plotted against time (seconds) (Figure 10). It may be observed that reaction to acid was low in the various brands of toothpaste after 100 seconds. Thereafter, 
increased acid reaction could be observed. After 500 seconds, all the test samples recorded near plateaulike graph lines suggesting no significant changes were occurring in the quanta of gas pressure generated. The Oralwise sample produced the lowest curve (d), while the control had the widest curve(a). Notwithstanding this, Colgate Sensitive brand of toothpaste had the lowest initial rate of acid reaction, while the eggshell powder (control) had the highest initial rate (Figure 11).

\section{DISCUSSION}

Despite general improvements in oral health status, dental caries still remains a significant public concern posing a grave challenge for the oral health care provider in mitigation and prevention. Published literature suggests that brushing regularly with well formulated fluoride toothpastes can prevent the onset of this disease..$^{9,10,26,27}$ In the present in vitro study, eggshell powder was used as a substitute for human tooth material to verify the effectiveness of five commercially available toothpastes in the prevention of dental caries. SEM and EDX were used to study the surface morphology and the calcium and phosphate composition of the brands of toothpastes before and after agitation with eggshell powder.

Calcium phosphate is regarded as being fundamental for the formation of teeth. ${ }^{28}$ Based on the EDX elemental analysis (Table 2), calcium phosphate ions were evidently present post agitation with eggshell powder. Notably, the SEM micrographs of the tested brands of toothpastes (Figure 4-7) were able to show net differences pre and post agitation with eggshell powder, which suggests the formation of enamel like hydroxyapatite layer in all brands of toothpastes. In light of the differences in the surface morphology as well as the elemental composition of the tested brands of toothpastes, it can be inferred that eggshell will be suitable as a human tooth substitute for in vitro assessment of erosive attack. This is in agreement with Haghgoo, Mehran (29) that eggshell powder could be used as alternative for hydroxyapatite since it contain calcium, phosphorus and other mineral element.

Furthermore, effectiveness the toothpaste against $\mathrm{HCl}$ acid attacks was evaluated using both gas-displacement and pressure sensor tests. The data generated from the gas tests suggest that Aquafresh brand of toothpaste is more likely to produce the less volume of gas when reacted with acids (Figure 8 and 9). However, the volume of gas generated from the test samples is not indicative of the effectiveness of the brands of toothpaste in the prevention of acid attacks. As reported in Figure 11, Colgate Sensitive had the lowest initial rate of acid attack, followed by Sensodyne, hence their ability to prevent acid reaction with the tooth that causes dental caries. Overall, all the tested brands of toothpaste tend to be effective in the prevention of dental caries by reducing the reaction of the tooth enamel to $\mathrm{HCl}$ acid exposure.

Importantly, and in respect to time of protection, clear differences in the prevention of acid attacks were observed between the tested brands of toothpastes and control (eggshell powder dissolved in water). From the graphical results shown in Figure 10, as expected, the various brands of toothpastes resulted in less acid reaction than the control. For instance, the tested toothpastes provided greatest protection to the tooth surface in less than 2 minutes (100 seconds) after acid attacks. In contrast, more acidic reaction could be observed for the control sample even after 8-10 minutes (above 500 seconds) exposure to the acids. This suggests that human tooth can react with acid more easily without any protection offered by toothpastes. Hence, it can be gathered that the composition of the tested toothpastes, particularly the fluoride content is responsible for the protection of the tooth against acid attacks. Kallahalli, Sanjay (30) reported that fluorides are abundantly used in many oral health products including toothpastes and mouth rinses as they help in caries prevention by reducing dental caries between 30 and $70 \%$ compared with no fluoride therapy. The findings from this study therefore confirmed the effectiveness of fluoride-based toothpastes in the prevention of dental caries.

The protective effect against erosion observed for Colgate Sensitive and Sensodyne, for example, is in line with previous studies. Lombardini, Ceci ${ }^{31}$ reported that Colgate Sensitive Pro Relief was more effective than Sensodyne in the protection of enamel against acid attacks. Kato, Lancia, ${ }^{16}$ who used bovine enamel, observed that Colgate Sensitive and Sensodyne Original had the best protective effect against erosive acids.

Drawing from the above discussion, it is sufficient to say that the eggshells model was successfully used to evaluate the protective effect of commercial toothpaste against acid attacks. This may be important, particularly in the context of oral health care, as eggshells present a suitable, cheaper, and readily available alternative source to the use of bovine and human enamel models in examining the protective effect of commercial toothpaste. The study suggests that gas displacement and the use of a pressure sensor present a new method of evaluating the rate of reaction between enamel and acids.

\section{LIMITATIONS}

The gas displacement and pressure tests cannot measure mineral dissolution and surface changes in the eggshell model. Future research could be directed at an examination of the surface of the eggshell model post acid exposure. This would help explain the mechanisms associated with the protective effect of the tested toothpastes by evaluating the mineral dissolution in the eggshell model.

\section{CONCLUSION}

Eggshell powder can be used as a substitute for human tooth in an in vitro experiment. Notably, this study conclusively showed that of the test products, Colgate Sensitive is the most effective brand of toothpaste against acid attacks, while Oralwise is the least effective. However, all brands of the tested toothpastes did lower the rate of reaction between $\mathrm{HCl}$ acid and eggshell powder tooth substitute, suggesting their ability to protect the tooth from acids that cause dental caries.

\section{Acknowledgment}

The authors acknowledge the financial support from the National Research Foundation of South Africa (No. 104824).

\section{References}

1. Karpiński TM, Szkaradkiewicz AK. Microbiology of dental caries. Journal of Biology and Earth Sciences 2013;3(1):21-4

2. Maharani DA, Rahardjo A. Mothers' dental Health Behaviors 
and Mother-Child's Dental Caries Experiences: Study of a Suburb Area in Indonesia. Makara Journal of Health Research 2013:72-6.

3. Teke GN, Enongene NG, Tiagha AR. In vitro Antimicrobial activity of some commercial toothpastes. Int J Curr Microbiol App Sci. 2017;6(1):433-46.

4. Inetianbor J, Ehiowemwenguan G, Yakubu J, Ogodo A. Invitro antibacterial activity of commonly used toothpastes in Nigeria against dental pathogens. Journal of Advanced Scientific Research 2014;2:40-5.

5. Hay SI, Jayaraman SP, Truelsen T, Sorensen RJ, Millear A, Giussani G, et al. GBD 2015 Disease and Injury Incidence and Prevalence Collaborators. Global, regional, and national incidence, prevalence, and years lived with disability for 310 diseases and injuries, 1990-2015: a systematic analysis for the Global Burden of Disease Study 2015. Lancet 2017;389(10064):E1-E.

6. VosT FA, Naghavi M, Lozano R, Michaud C, Ezzati M, Shibuya $\mathrm{K}$, et al. Years lived with disability (YLDs) for 1160 sequelae of 289 diseases and injuries 1990-2010: a systematic analysis for the Global Burden of Disease Study 2010. Lancet 2012;380(9859):2163-96.

7. Harris R, Nicoll AD, Adair PM, Pine CM. Risk factors for dental caries in young children: a systematic review of the literature. Community Dental Health 2004;21(1):71-85.

8. Begzati A, Berisha M, Meqa K. Early childhood caries in preschool children of Kosovo-a serious public health problem. BMC Public Health 2010;10(1):788.

9. Almosa NA, Lundgren T, Aldrees AM, Birkhed D, Kjellberg $\mathrm{H}$. Diagnosing the severity of buccal caries lesions in governmental and private orthodontic patients at debonding, using the ICDAS-II and the DIAGNOdent Pen. The Angle Orthodontist 2013;84(3):430-6.

10. Krithikadatta J, Fredrick C, Abarajithan M, Kandaswamy D. Remineralisation of occlusal white spot lesion with a combination of $10 \%$ CPP-ACP and $0.2 \%$ sodium fluoride evaluated using Diagnodent: a pilot study. Oral Health and Preventive Dentistry 2013;11(2):191-6.

11. Hooper S, Newcombe RG, Faller R, Eversole S, Addy M, West $\mathrm{N}$. The protective effects of toothpaste against erosion by orange juice: studies in situ and in vitro. Journal of Dentistry 2007;35(6):476-81.

12. Pannuti CM, Mattos JPd, Ranoya PN, Jesus AMd, Lotufo RFM, Romito GA. Clinical effect of a herbal dentifrice on the control of plaque and gingivitis: a double-blind study. Pesquisa Odontológica Brasileira 2003;17(4):314-8.

13. Anusavice KJ, Antonson SA. Materials and processes for cutting, grinding, finishing, and polishing. In: Anusavice KJ, Shen C, Rawls HR, editors. Phillips' Science of Dental Materials St. Louis:: Saunders,; 2013. p. 236.

14. Itthagarun A, Wei S. Analysis of fluoride ion concentrations and in vitro fluoride uptake from different commercial dentifrices. International Dental Journal 1996:46(4):357-61.

15. Goldman AS, Yee R, Holmgren CJ, Benzian H. Global affordability of fluoride toothpaste. Globalization and Health 2008;4(1):7.

16. Kato M, Lancia M, Sales-Peres S, Buzalaf M. Preventive effect of commercial desensitizing toothpastes on bovine enamel erosion in vitro. Caries Research 2010;44(2):85-9.

17. Colombo M, Mirando M, Rattalino D, Beltrami R, Chiesa M, Poggio C. Remineralising effect of a zinc-hydroxyapatite toothpaste on enamel erosion caused by soft drinks: Ultrastructural analysis. Journal of Clinical and Experimental Dentistry 2017;9(7):e861.

18. Jensdottir T, Holbrook P, Nauntofte B, Buchwald C, Bardow A. Immediate erosive potential of cola drinks and orange juices. Journal of Dental Research 2006;85(3):226-30.

19. Brown CJ, Smith G, Shaw L, Parry J, Smith AJ. The erosive potential of flavoured sparkling water drinks. International Journal of Paediatric Dentistry 2007;17(2):86-91.

20. Neel EAA, Aljabo A, Strange A, Ibrahim S, Coathup M, Young AM, et al. Demineralisation-remineralisation dynamics in teeth and bone. International Journal of Nanomedicine 2016;11:4743.

21. Scaramucci T, Carvalho JC, Hara AT, Zero DT. Causes of dental erosion: intrinsic factors. Dental Erosion and its Clinical Management: Springer; 2015. p. 35-67.

22. Hincke MT, Nys Y, J G, Rodriguez-Navarro AB, Mckee MD. The eggshell: structure, composition and mineralisation. Frontiers Bioscience 2012;17:1266-80.

23. Onwubu SC, Vahed A, Singh S, Kanny K. Physico-chemical characterisation of a dental eggshell powder abrasive material. Journal of Applied and Biomaterials and Functional Materials. 2017.

24. Macha IJ, Ozyegin L, Oktar FN, Ben-Nissan B. Conversion of ostrich eggshells (Struthio camelus) to calcium phosphates. Journal Australian Ceramic Society 2015;51:125-33.

25. Kattimani V, Lingamaneni KP, Chakravarthi PS, Kumar TS, Siddharthan A. Eggshells-derived hydroxyapatite: A new era in bone regeneration. Journal Craniofacial Surgery 2016;27:112-7.

26. Rahardjo A, Nugraheni DDT, Humaira G, Adiatman M, Maharani DA. Efficacy of toothpaste containing nano calcium in dentin remineralisation. Makara Journal of Health Research2015:43-7.

27. Yazıcıoğlu $\mathrm{O}$, Ulukapı $\mathrm{H}$. The investigation of non-invasive techniques for treating early approximal carious lesions: an in vivo study. International Dental Journal 2014;64(1):1-11.

28. Ma J, Johns RA, Stafford RS. Americans are not meeting current calcium recommendations. The American Journal of Clinical Nutrition 2007;85(5):1361-6.

29. Haghgoo R, Mehran M, Ahmadvand M, Ahmadvand MJ. Remineralisation effect of eggshell versus nano-hydroxyapatite on caries-like lesions in permanent teeth (in vitro). Journal of International Oral Health 2016;8(4):435.

30. Kallahalli M, Sanjay V, Govinduraju P, Darshana B, Bhadravathi $\mathrm{V}$, Antharasanahalli S. Antimicrobial efficacy of commercially available toothpastes. Journal Young Pharmacists 2015;7(3):187-93.

31. Lombardini M, Ceci M, Colombo M, Bianchi S, Poggio C. Preventive effect of different toothpastes on enamel erosion: AFM and SEM studies. Scanning 2014;36(4):401-10. 